\title{
Populatiescreening op diabetes mellitus type 2 levert weinig op
}

Verslag van het ADDITION-onderzoek

\author{
Paul Janssen, Kees Gorter, Ronald Stolk, Guy Rutten
}

\begin{abstract}
Inleiding
De prevalentie van diabetes neemt wereldwijd snel toe. ${ }^{1}$ In Nederland was de prevalentie in 2003 ongeveer 3\%. ${ }^{2}$ Omdat diabetes mellitus type 2 in de beginfase vaak asymptomatisch is, blijft de aandoening niet zelden jarenlang ongediagnosticeerd. ${ }^{3}$ Op het moment van diagnosestelling zijn daarom dikwijls al complicaties aanwezig. ${ }^{4,5}$ Om deze redenen zou men kunnen overwegen de bevolking te screenen op diabetes; er is dan ook een roep om zo'n screening. Het nut daarvan is niet bewezen ${ }^{6}$, maar de American Diabetes Association acht opportunistische screening op diabetes van hoogrisicogroepen in een klinische setting wel geïndiceerd. ${ }^{7}$ Niemand weet eigenlijk hoe screening op diabetes het best kan worden uitgevoerd. ${ }^{8-11}$ Veel programma's combineren populatiescreening en screening van personen met een hoog risico. ${ }^{12}$ Deze programma's volgen meestal een stapsgewijze aanpak: met een vragenlijst identificeert men in de algemene bevolking personen die een verhoogd risico op onontdekte diabetes hebben, en bij deze personen doet men vervolgens een nuchtere glucosemeting. ${ }^{13}$
\end{abstract}

\section{Samenvatting}

Janssen P, Gorter K, Stolk R, Rutten G. Populatiescreening op diabetes mellitus type 2 levert weinig op: Verslag van het ADDITION-onderzoek. Huisarts Wet 2009;52(5):225-30.

Inleiding Tien jaar geleden was in Nederland van ongeveer de helft van de mensen met diabetes mellitus type 2 niet bekend dat zij deze aandoening hadden. Sinds er een richtlijn is gekomen en huisartsen de aandoening actiever zijn gaan opsporen, zijn de prevalentiecijfers voor diabetes gestegen. Nog steeds echter is er een roep om populatiescreening. Wij hebben onderzocht of zo'n screening effectief zou zijn.

Methode Tussen mei 2002 en april 2004 screenden wij 56.978 patiënten van 79 huisartsenpraktijken in zuidwest Nederland, tussen 50 en 70 jaar oud en zonder bekende diabetes. De deelnemers ontvingen een risicovragenlijst; wie boven de drempelwaarde scoorde kreeg een glucosemeting.

Resultaten Wij diagnosticeerden diabetes mellitus type 2 bij in totaal 586 personen (1,0\%), 'epidemiologische diabetes' bij 222 personen $(0,4 \%)$ en een stoornis in de glucosetolerantie bij 1011 personen $(1,8 \%)$. De deelnemers scoorden hoger op de risicovragenlijst naarmate het glucosemetabolisme sterker gestoord was. De uitval was echter hoog. Onder de deelnemers die in aanmerking kwamen voor een orale glucosetolerantietest - de laatste
Een andere vorm van screening is case-finding. Daarbij verricht de huisarts op het spreekuur gericht glucosemetingen bij patiënten die een verhoogd risico hebben op diabetes mellitus type 2. Het Nederlands Huisartsen Genootschap adviseert case-finding bij personen ouder dan 45 jaar die een verhoogde bloeddruk hebben, een verhoogd cholesterolgehalte, reeds hart- en vaatziekten, overgewicht of naaste verwanten met diabetes mellitus type 2, en bij personen van Turkse, Hindoestaanse of Surinaamse afkomst. ${ }^{14}$

De Gezondheidsraad achtte, in een advies uit 2004, een algemene screening van de bevolking op diabetes niet aangewezen zolang de effectiviteit voor het verminderen van gezondheidsschade en sterfte niet vaststaat. ${ }^{15}$ Het internationale ADDITION-project (Anglo-Danish-Dutch Study of intensive treatment in people with screen detected diabetes in primary care) onderzoekt of screening op onontdekte diabetes mellitus type 2 en in aansluiting daarop intensieve behandeling voordelen heeft voor de patiënt. ${ }^{16}$ In het kader van ADDITION-Nederland onderzochten wij de effectiviteit van twee screeningsprocedures.

stap in de diagnostiek - was de uitval zelfs 23,4\%.

Conclusie In Nederland is de opbrengst van een populatiescreening op diabetes laag en is de uitval juist in de hoogrisicogroep groot. Gegeven de afnemende prevalentie van ongediagnosticeerde diabetes en de aanwezigheid van goed georganiseerde huisartsenpraktijken is case-finding een betere manier om diabetes op te sporen.

Universitair Medisch Centrum Utrecht, Julius Centrum voor Gezondheidswetenschappen en Eerstelijns Geneeskunde, Postbus 85060, 3508 AB Utrecht: dr. P.G.H. Janssen, huisarts-onderzoeker, dr. K.J. Gorter, huisarts-onderzoeker, prof.dr. G.E.H.M. Rutten, hoogleraar Diabetologie in de Huisartsgeneeskunde. Universitair Medisch Centrum Groningen, Universiteit Groningen, afdeling Epidemiologie: prof.dr. R.P. Stolk, hoogleraar Klinische epidemiologie.

Correspondentie: p.janssen@nhg.org

Mogelijke belangenverstrengeling: het ADDITION-Nederland-onderzoek is mogelijk gemaakt door onvoorwaardelijke financiële steun van NovoNordisk, GlaxoSmithKline en Merck.

Dit onderzoek is eerder gepubliceerd als: Janssen PG, Gorter KJ, Stolk RP, Rutten GE. Low yield of population-based screening for Type 2 diabetes in the Netherlands: the ADDITION Netherlands study. Fam Pract 2007;24:555-61. 
Wat is bekend?

- Veel personen met diabetes mellitus type 2 zijn niet als zodanig gediagnosticeerd

Een screening van de algemene bevolking (populatiescreening) op diabetes lijkt daarom aan te bevelen.

\section{Wat is nieuw?}

De opbrengst van zo'n populatiescreening is laag (rond de 1\%), waarschijnlijk omdat de prevalentie van ongediagnosticeerde diabetes in Nederland al enige tijd daalt dankzij case-finding.

- Voor het opsporen van ongediagnosticeerde diabetes is casefinding in de huisartsenpraktijk dan ook een effectiever middel dan populatiescreening

\section{Methode}

In totaal 56.978 patiënten uit 79 huisartsenpraktijken in zuidwest Brabant, tussen 50 en 70 jaar oud en niet reeds bekend met diabetes, ontvingen een uitnodiging om deel te nemen aan een screeningsprogramma dat kon bestaan uit een vierstaps- of een driestapsprocedure. Deelnemers gaven schriftelijk toestemming voor het onderzoek.

De eerste screeningsprocedure bestond uit vier stappen en duurde van mei 2002 tot januari 2003. Aan deze procedure namen 29.251 patiënten deel van 41 praktijken. De tweede screeningsprocedure had drie stappen, duurde van juli 2003 tot april 2004 en omvatte 27.727 deelnemers uit 38 praktijken op grotere afstand van het regionale laboratorium

Vóór de screening was de prevalentie van reeds bekende diabetes (in alle leeftijdsgroepen) in de praktijken in de eerste en tweede procedure respectievelijk 3,2\% en 3,0\%. Tabel 1 geeft de karakteristieken van de deelnemende praktijken.

\section{Screeningsprogramma}

Een uitnodigingsbrief, ondertekend door de eigen huisarts, werd verstuurd naar het huisadres van de patiënten. Bijgesloten werd een toestemmingsformulier en een gevalideerde risicovragenlijst (range 0-29 punten) met items over leeftijd, geslacht, BMI, familieanamnese voor diabetes, dorst, gebruik van antihypertensiva, pijn op de borst tijdens inspanning, claudicatioklachten en regelmatig fietsen. ${ }^{17,18} \mathrm{Bij}$ een score op de vragenlijst boven een tevoren vastgestelde drempelwaarde konden deelnemers zich melden voor een diagnostische glucosemeting. Wie een score onder de drempelwaarde had maar zich toch voor een glucosemeting

meldde, werd niet geweigerd. De glucosemetingen vonden plaats op locaties in de nabije omgeving van de deelnemers, binnen en buiten kantooruren. De deelnemers konden de meting zo nodig ook op een andere dag of zelfs op zaterdag laten verrichten. Als de eerste glucosemeting aangaf dat vervolgmetingen nodig waren, verrichtten wij die in de week daarna. Voor de diagnose diabetes golden de criteria van de World Health Organization uit 1999. ${ }^{19}$ Wij bepaalden het plasmaglucose met de peroxidasemethode en het capillaire glucose met een HemoCue ${ }^{\circledR}$ B-Glucose Analyser (glucosedehydrogenasemethode). ${ }^{20}$

\section{Vierstapsprocedure}

De eerste stap van deze screeningsprocedure bestond uit de risicovragenlijst. Deelnemers met een score hoger dan vier punten ontvingen, als tweede stap, een uitnodiging voor een willekeurige capillaire glucosemeting (random blood glucose, RBG). De vierstapsprocedure was opgezet om behalve op diabetes ook op impaired glucose tolerance (IGT) te screenen (de nuchtere glucosewaarde is dan normaal maar de twee-uurswaarde is licht verhoogd tot 7,8$11,0 \mathrm{mmol} / \mathrm{l}$ ). Daarom was het afkappunt in deze procedure twee punten lager dan in de driestapsprocedure.

Als derde stap voerden wij bij personen met een $\mathrm{RBG} \geq 5,5 \mathrm{mmol} / \mathrm{l}$ een nuchtere glucosemeting uit (fasting blood glucose, FBG). Deelnemers met een $R B G \geq 11,1 \mathrm{mmol} / \mathrm{l}$ en een $\mathrm{FBG}>6,0 \mathrm{mmol} / \mathrm{l} \mathrm{kregen}$ de diagnose diabetes.

Deelnemers met een FBG $>6,0 \mathrm{mmol} / \mathrm{l}$ maar een $\mathrm{RBG}<11,1$ $\mathrm{mmol} / \mathrm{l}$ werden - als vierde stap - uitgenodigd voor een standaard 75 gram orale glucosetolerantietest (OGTT). Bij de OGTT controleerden wij de waarden in veneus bloed of plasma. Indien de nuchtere glucosewaarde in veneus plasma (fasting plasma glucose, FPG) $\geq 7,0 \mathrm{mmol} / \mathrm{l}$ was, of de twee-uurs plasmaglucosewaarde (two hours plasma glucose, 2-hPG) $\geq 11,1 \mathrm{mmol} / \mathrm{l}$, stelden wij de diagnose diabetes.

Personen bij wie de OGTT geen diabetische glucosewaarde aangaf, categoriseerden wij als 'epidemiologische diabetes': in het screeningsprogramma is één diabetische glucosewaarde gevonden, maar dit is onvoldoende om de klinische diagnose diabetes te stellen

Ook deelnemers met een FBG tussen 5,2 en 6,0 mmol/l ondergingen als vierde stap een OGTT. Indien de OGTT bij deze personen een $2-h P G \geq 11,1 \mathrm{mmol} / \mathrm{l}$ aangaf (hun eerste diabetische glucosewaarde), kregen zij een tweede OGTT. Deelnemers met een $2-\mathrm{hPG} \geq 7,8 \mathrm{mmol} / \mathrm{l}$ maar $<11,1 \mathrm{mmol} / \mathrm{l}$ classificeerden wij als IGT, deelnemers met 2-hPG <

Tabel 1 Praktijkkarakteristieken

\begin{tabular}{lcc}
\hline Praktijken $(\mathrm{n}=79)$ & Vierstapsprocedure (\%)* & Driestapsprocedure $(\%) *$ \\
Solopraktijk & 54 & 39 \\
Stadspraktijk & 51 & 32 \\
$\leq 10 \%$ patiënten uit etnische minderheidsgroepen & 15 & 8 \\
Praktijkassistente betrokken bij diabeteszorg & 63 & 42 \\
POH betrokken bij diabeteszorg & 38 & 58 \\
Samenwerking met diabetesverpleegkundige & 65 & 50 \\
Speciaal diabetesspreekuur & 65 & 61 \\
Instelling op insuline & 75 & 68 \\
\hline
\end{tabular}

* Verschillen tussen beide procedures niet significant
$7,8 \mathrm{mmol} / \mathrm{l}$ classificeerden wij als impaired fasting glucose (IFG) indien hun FBG tussen 5,6 en 6,0 mmol/l lag, dan wel hun FPG tussen 6,1 en $7,0 \mathrm{mmol} / \mathrm{l}$. IFG wil zeggen dat de nuchtere glucosewaarde verhoogd maar niet-diabetisch is, en de twee-uurswaarde normaal. Tot besluit stuurden wij de deel- 
nemers een brief met de resultaten van de glucosemetingen en bespraken we de implicaties met hen. Ook hun huisartsen werden hiervan in kennis gesteld.

\section{Driestapsprocedure}

Uit kostenoverwegingen beperkten wij ons in deze procedure tot capillaire metingen en voerden wij geen glucosemetingen uit buiten kantooruren. Personen met een score van 6 of meer op de risicovragenlijst nodigden wij uit voor stap 2, een FBG-meting; de RBG-meting verviel. Bij personen met een FBG > 6,0 mmol/l volgde stap 3, een OGTT met capillaire glucosebepaling. Resulteerde de OGTT in een diabetische glucosewaarde, dan stelden wij de diagnose diabetes, zo niet dan was de diagnose epidemiologische diabetes. Deelnemers met een FBG tussen 5,6 en 6,0 mmol/l classificeerden wij als IFG; zij kregen geen OGTT.

\section{Analyse}

De statistische analyses voerden wij uit met SPSS. De karakteris-

Figuur 1 De vierstapsprocedure

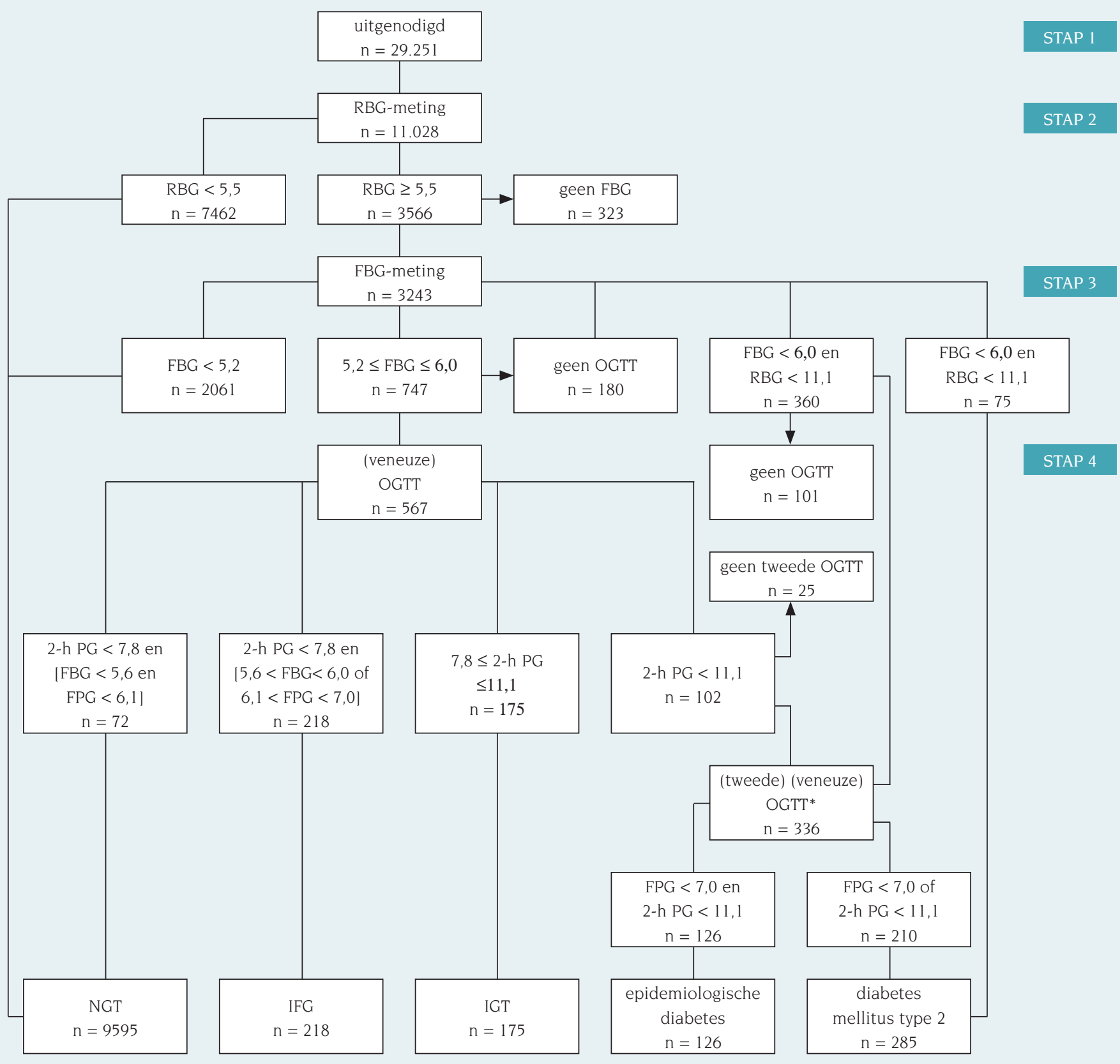

* Tweede OGTT voor personen met FBG $\geq 5,2 \mathrm{mmol} / \mathrm{l}$ en $\leq 6,0 \mathrm{mmol} / \mathrm{l}$, eerste OGTT voor personen met FBG $>6,0 \mathrm{mmol} / \mathrm{l}$ en RBG $<11,1 \mathrm{mmol} / \mathrm{I}$. Binnen de stippellijnen: uitvallers.

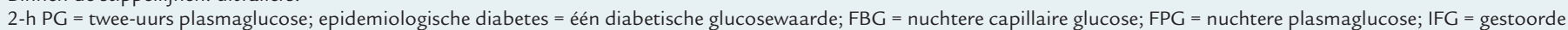
nuchtere glucose; IGT = gestoorde glucosetolerantie; NGT = normale glucosetolerantie; OGTT = orale glucosetolerantietest; RBG = willekeurige capillaire glucose. 
tieken van de deelnemers en de procedures vergeleken wij met de student-t-test en de chikwadraattest, de kenmerken van de praktijken in de twee procedures met de chikwadraattest. De associatie tussen de risicoscore en de verschillende glucosetolerantiecategorieën onderzochten wij met een lineaire regressieanalyse; een $p$-waarde $<0,05$ was significant.

\section{Resultaten}

De deelnemers stuurden de vragenlijsten niet terug maar namen ze mee naar de screening.

Voor de eerste glucosemeting meldden zich in totaal 17.883 $(31,4 \%)$ van de 56.978 deelnemers (11.028 uit de vierstaps- en 6855 uit de driestapsprocedure). Uiteindelijk stelden wij de diagnose diabetes mellitus type 2 bij 586 personen (1,0\% van de uitgenodigde deelnemers), epidemiologische diabetes bij 222 personen $(0,4 \%)$ en gestoorde glucoseregulatie (IFG of IGT) bij 1011 personen $(1,8 \%)$.

De uitval binnen de groep die in aanmerking kwam voor de OGTT was $23,4 \%$. In de deelnemende praktijken steeg de prevalentie van bekende diabetes in de leeftijdsgroep 50- tot 70-jarigen van 6,1\% vóór de screening tot 7,0\% na de screening.

\section{Vierstapsprocedure}

Van de 29.251 uitgenodigde personen ondergingen er 11.028 $(37,7 \%)$ een RBG-meting (figuur 1) en 3243 (11,1\%) een FBGmeting. Uiteindelijk stelden wij bij 285 personen (1,0\% van de uitgenodigde personen) de diagnose diabetes mellitus type 2 , bij
$126(0,4 \%)$ de diagnose epidemiologische diabetes, bij $175(0,6 \%)$ IGT en bij 218 (0,7\%) IFG.

Na de RBG-meting verschenen 323 (9,1\%) van de 3566 personen met een score $\geq 5,5 \mathrm{mmol} / \mathrm{l}$ niet voor de FBG-meting, van de 747 personen met een FBG tussen 5,2 en 6,0 mmol/l kwamen er 180 $(24,1 \%)$ niet opdagen voor de OGTT en van de 462 personen met een indicatie voor een tweede OGTT vielen er 126 (27,3\%) uit. Voor de RBG-meting meldden zich ook 1467 personen (5,0\% van de uitgenodigde personen) hoewel hun risicoscore niet boven de drempelwaarde uitkwam. In deze groep ontdekten wij 19 personen met diabetes, 7 met epidemiologische diabetes, 12 met IGT en 20 met IFG.

\section{Driestapsprocedure}

Van de 27.727 uitgenodigde personen meldden zich 6855 (24,7\%) voor de FBG-meting (figuur 2) en ondergingen 397 personen $(1,4 \%)$ een OGTT. Bij 301 deelnemers $(1,1 \%)$ werd diabetes gediagnosticeerd, bij 96 (0,3\%) epidemiologische diabetes en bij 681 (2,5\%) IFG. Het was niet mogelijk IGT te diagnosticeren omdat de OGTT alleen werd uitgevoerd bij personen met een FBG > 6,0 mmol/l. De uitval onder de 489 personen die voor de OGTT waren uitgenodigd, was $92(18,8 \%)$.

In deze procedure meldden 1451 personen $(5,2 \%)$ zich voor een FBG-meting hoewel hun risicoscore te laag was voor een indicatie. In deze groep ontdekten wij 43 personen met diabetes, 8 met epidemiologische diabetes en 70 met IFG.

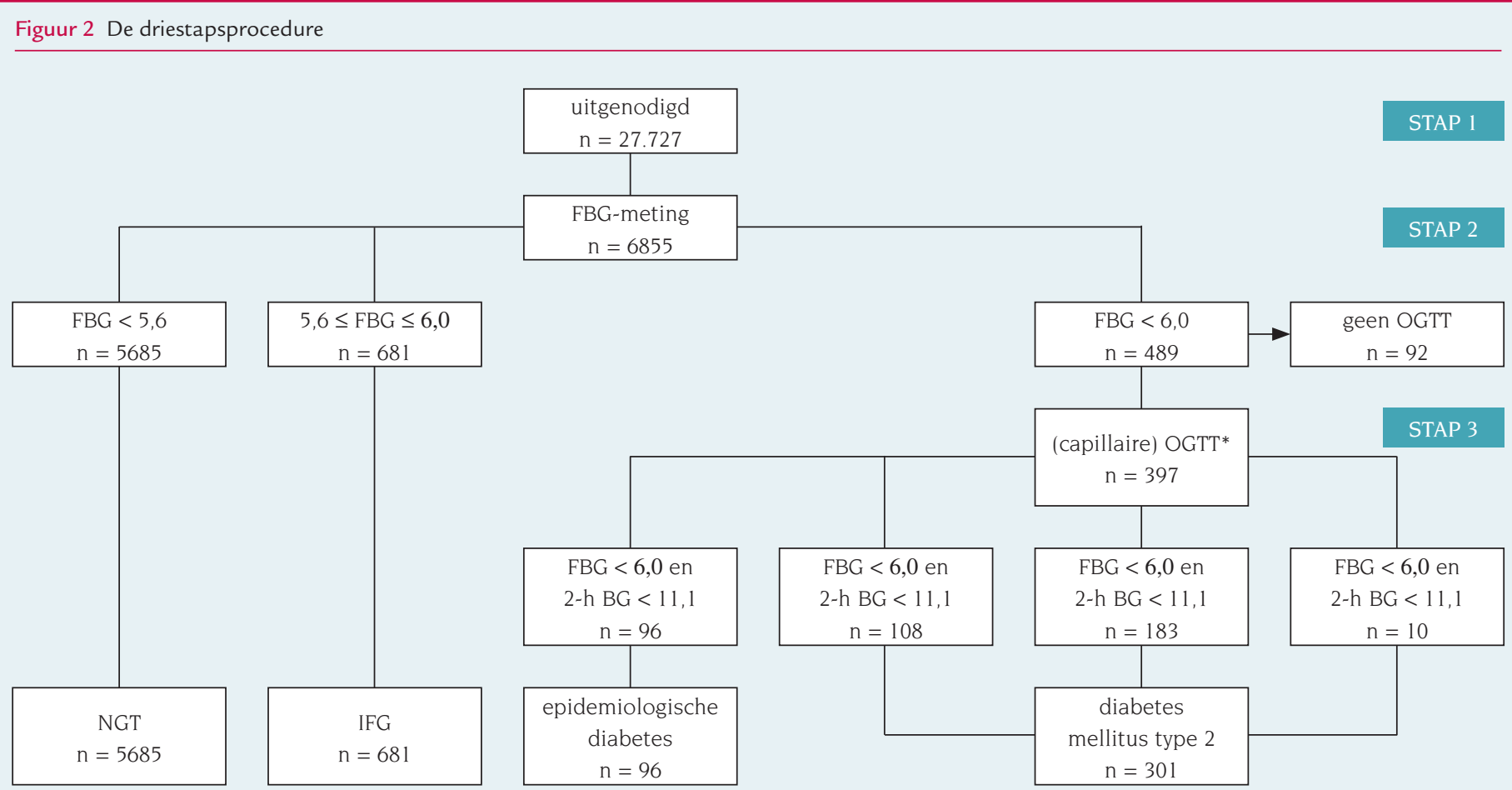

Binnen de stippellijnen: uitvallers.

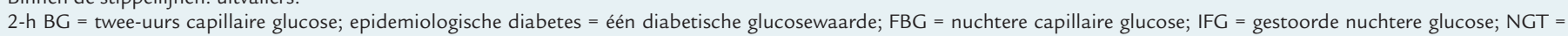
normale glucosetolerantie; OGTT = orale glucosetolerantietest. 


\section{Vergelijking van beide screeningsprocedures}

In tabel 2 presenteren we de karakteristieken van de twee screeningsprocedures. In beide procedures bedroeg het percentage ontdekte personen met diabetes $0,9 \%$, niet meegerekend degenen die een risicoscore onder de drempelwaarde hadden maar die toch diabetes bleken te hebben. We geven hierna de gemiddelde risicoscores $( \pm \mathrm{SD})$ in elke diagnostische categorie.

In de vierstapsprocedure was de gemiddelde risicoscore van deelnemers met een normale glucosetolerantie (NGT) 7,5 ( $\pm 4,3)$. De gemiddelde risicoscore van deelnemers met IFG was $8,5( \pm 4,9)$, met IGT 8,9 $( \pm 4,5)$ en met epidemiologische diabetes 9,8 $( \pm 5,2)$. De risicoscore van diabetespatiënten bedroeg 10,5 $( \pm 5,0)$.

In de driestapsprocedure waren de gemiddelde risicoscores voor NGT 8,0 $( \pm 4,1)$, voor IGT 9,2 $( \pm 4,2)$, voor epidemiologische diabetes 10,0 $( \pm 4,2)$ en voor diabetes mellitus type $210,3( \pm 4,7)$.

In beide procedures was de risicoscore hoger als het glucosemetabolisme sterker was gestoord (trendtest: $p<0,001$ ).

Van de 41 praktijken in de vierstapsprocedure waren $22(53,7 \%)$ solopraktijken, 20 (48,8\%) plattelandspraktijken en 5 (12,2\%) praktijken met meer dan $10 \%$ patiënten uit etnische minderheden. Onder de 38 praktijken in de driestapsprocedure bevonden zich $15(39,5 \%)$ solopraktijken $(p=0,207), 26(68,4 \%)$ plattelandspraktijken $(p=0,077)$ en $1(2,6 \%)$ praktijk met meer dan $10 \%$ patiënten uit etnische minderheden $(p=0,109)$. De verschillen waren echter niet significant.

\section{Beschouwing}

Eenderde van de uitgenodigde personen verscheen voor een eerste glucosemeting. Deze opkomst komt overeen met die van het onderzoek in Hoorn. ${ }^{17}$ Ongeveer een kwart van de patiënten die waren uitgenodigd voor de OGTT kwam niet opdagen. De opbrengst van ons screeningsprogramma was laag: slechts 1,0\% van de geïnviteerde personen bleek uiteindelijk diabetes te hebben. De opbrengst van de vierstapsprocedure $(1,0 \%)$ verschilde overigens niet significant van die van de driestapsprocedure $(1,1 \%)$.
Bij de interpretatie van deze bevindingen moeten we ons realiseren dat een aanzienlijk aantal mensen met een mogelijk verhoogd risico op diabetes mellitus type 2 niet inging op onze uitnodiging. De uitval onder hoogrisicopersonen en de karakteristieken van de deelnemende praktijken waren in beide procedures vergelijkbaar, dus het is niet waarschijnlijk dat deze variabelen de vergelijking van de opbrengsten hebben verstoord. Wel kunnen verschillen in de gebruikte testmethoden de opbrengsten hebben beïnvloed. Wij vonden een toename van $0,9 \%$ in de prevalentie van bekende diabetes na de screening. Het onderzoek in Hoorn rapporteerde in de periode 1989-1992 een toename van bijna 5\%, zij het in een iets andere leeftijdsgroep (50-75 jaar). ${ }^{21}$ De opbrengst van de screening (ontdekte personen met diabetes als proportie van het aantal uitgenodigde personen) was in het onderzoek in Hoorn over de periode 1998-2000 1,9\%, bijna tweemaal zoveel als in ons screeningsprogramma. ${ }^{17}$ Halverwege de jaren '90 was naar schatting de helft van alle mensen met diabetes niet als zodanig gediagnosticeerd, maar we mogen concluderen dat dit niet langer het geval is. In Nederland is case-finding op diabetes in de huisartsenpraktijk gebruikelijker geworden, en de weerslag daarvan is een sterke toename van de prevalentie van diabetes in de late jaren negentig. ${ }^{2}$ We willen echter benadrukken dat ons onderzoek niet was opgezet om de werkelijke prevalentie van niet-gediagnosticeerde diabetes vast te stellen. Die is nog steeds onbekend. Maar het is aannemelijk dat de lage opbrengst van ons screeningsprogramma samenhangt met de steeds lagere prevalentie van ongediagnosticeerde diabetes. In het Deense ADDITION-onderzoek vonden Christensen et al. een toename van slechts $0,6 \%$ in de prevalentie van bekende diabetes na screening (leeftijdscategorie 40-70 jaar), voornamelijk omdat een groot aantal mensen niet deelnam aan de screening. ${ }^{11}$ De auteurs concludeerden dat populatiescreening op diabetes niet effectief is.

In ons onderzoek was met name het aantal uitvallers onder diegenen die een OGTT zouden moeten ondergaan groot. De deelnemers die daarvoor een uitnodiging ontvingen, hadden al één diabetische glucosewaarde, en dat maakt het aannemelijk dat zich

Tabel 2 Resultaten van de twee screeningsprocedures

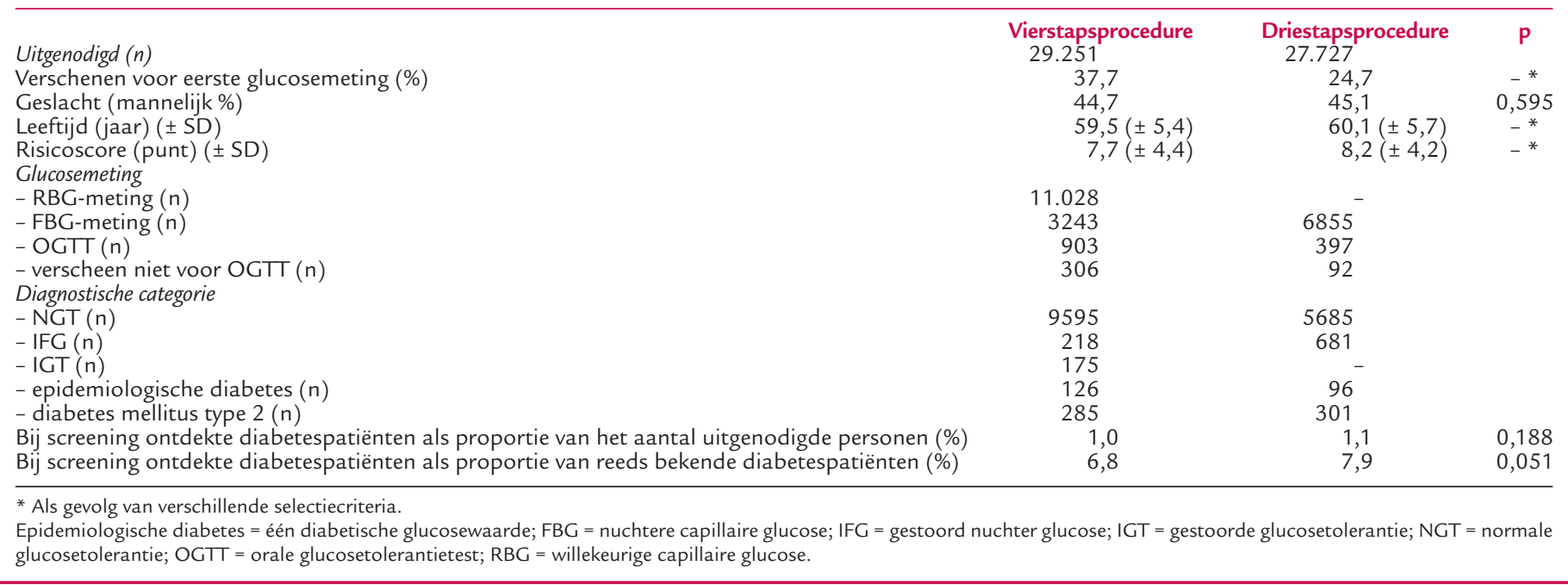


onder de uitvallers veel personen met diabetes bevinden.

Tegen deze achtergrond kan men beargumenteren dat case-finding in de huisartsenpraktijk een geschikter middel is om niet-gediagnosticeerde diabetes mellitus type 2 op te sporen dan populatiescreening. Screeningsprogramma's zijn duur en kosten veel tijd, case-finding heeft deze nadelen niet. In Nederland is aan noodzakelijke voorwaarden voldaan: praktisch de gehele bevolking is ingeschreven in een huisartsenpraktijk en de dagelijkse diabeteszorg in de praktijken is in het algemeen goed georganiseerd - al is verbetering zeker mogelijk en wenselijk. ${ }^{22}$ Als men verder bedenkt dat screening een continu proces hoort te zijn, is case-finding ook hier in het voordeel ten opzichte van andere strategieën. ${ }^{23}$ En case-finding heeft nog een ander voordeel: de mogelijkheid personen op te sporen die als gevolg van een gestoorde glucosetolerantie een verhoogd risico hebben op cardiovasculaire ziekten. ${ }^{24}$ Wij vonden dat de mate van glucose-intolerantie samenhing met de risicoscore: hoe hoger de score, hoe slechter de glykemische controle. Het aanzienlijke aantal personen met een gestoorde glucosetolerantie noopt tot een proactieve benadering teneinde hun cardiovasculair risico te reduceren. ${ }^{25}$

Samenvattend concluderen wij dat de opbrengst van populatiescreening op diabetes in Nederland lager is dan was verwacht. Gezien de afnemende prevalentie van ongediagnosticeerde diabetes en de aanwezigheid van goed georganiseerde huisartsenpraktijken lijkt case-finding een geschikter middel om personen met ongediagnosticeerde diabetes te identificeren dan populatiescreening.

\section{Dankbetuiging}

De auteurs danken de directie, staf en diabetesverpleegkundigen van de Stichting Huisartsen Laboratorium (SHL) te Etten-Leur en de huisartsen en praktijkmedewerkers die participeerden in ADDITION-Nederland.

\section{Literatuur}

1 Wild S, Roglic G, Green A, Sicree R, King H. Global prevalence of diabetes: estimates for the year 2000 and projections for 2030. Diabetes Care 2004;27:1047-53.

2 Baan CA, Poos MJJC. Neemt het aantal mensen met diabetes mellitus toe of af? Bilthoven: RIVM, 2006. http://www.rivm.nl/vtv/object_document/o1260n17502.html, geraadpleegd maart 2009.

3 Harris MI, Klein R, Welborn TA, Knuiman MW. Onset of NIDDM occurs at least 4-7 years before clinical diagnosis. Diabetes Care 1992; 15:815-9

4 Rajala U, Laakso M, Qiao Q, Keinanen-Kiukaanniemi S. Prevalence of retinopathy in people with diabetes, impaired glucose tolerance and normal glucose tolerance. Diabetes Care 1998;21:1664-9.

5 Colagiuri S, Cull CA, Holman RR. Are lower fasting plasma glucose levels at diagnosis of type 2 diabetes associated with improved outcomes (UKPDS 61)? Diabetes Care 2002;25:1410-7.

6 Borch-Johnsen K, Lauritzen T, Glümer C, Sandbaek A. Screening for type 2 diabetes: Should it be now? Diabet Med 2003;20:175-81.
7 American Diabetes Association. Screening for diabetes mellitus type 2 (position statement). Diabetes Care 2004;27:S1 1-4.

8 Simmons D, Thompson CF, Engelgau MM. Controlling the diabetes epidemic: How should we screen for undiagnosed diabetes and dysglycaemia? Diabet Med 2005;22:207-12.

9 Ealovega MW, Tabaei BP, Brandle M, Burke R, Herman WH. Opportunistic screening for diabetes in routine clinical practice. Diabetes Care 2004;27:9-12.

10 Engelgau MM, Venkat Narayan KM, Herman WH. Screening for type 2 diabetes. Diabetes Care 2000;23:1563-80.

11 Christensen JO, Sandbaek A, Lauritzen T, Borch-Johnsen K. Population-based stepwise screening for type 2 diabetes is ineffective in general practice despite reliable algorithms. Diabetologia 2004;47:1566-73.

12 Lawrence JM, Bennett P, Young A, Robinson AM. Screening for diabetes in general practice: Cross sectional population study. BMJ 2001;323:548-51.

13 Glümer C, Jorgensen T, Borch-Johnsen K. Targeted screening for undiagnosed diabetes reduces the number of diagnostic tests. Inter99(8). Diabet Med 2004;21:874-80.

14 Rutten GEHM, De Grauw WJC, Nijpels, Goudswaard AN, Uitewaal PJM, Van der Does FEE, et al. NHG-Standaard Diabetes mellitus type 2. Huisarts Wet 2006;49:137-52.

15 Gezondheidsraad. Screening op type 2 diabetes [advies aan de minister van Volksgezondheid, Welzijn en Sport]. Den Haag: Gezondheidsraad, 2004. http://www.gr.nl, geraadpleegd maart 2009.

16 Lauritzen T, Griffin S, Borch-Johnsen K, Wareham NJ, Wolffenbuttel BHR, Rutten GEH. The ADDITION study: proposed trial of the costeffectiveness of an intensive multifactorial intervention on morbidity and mortality among people with type 2 diabetes detected by screening. Int J Obes Relat Metab Disord 2000;24:S6-11.

17 Spijkerman AM, Adriaanse MC, Dekker JM, Nijpels G, Stehouwer CDA, Bouter LM, et al. Diabetic patients detected by population-based stepwise screening already have a diabetic cardiovascular risk profile. Diabetes Care 2002;25:1784-9.

18 Ruige JB, De Neeling JND, Kostense PJ, Bouter LM, Heine RJ. Performance of an NIDDM screening questionnaire based on symptoms and risk factors. Diabetes Care 1997;20:491-6.

19 Alberti KG, Zimmet PZ. Definition, diagnosis and classification of diabetes mellitus and its complications. Part 1: diagnosis and classification of diabetes mellitus. Provisional report of a WHO consultation. Diabet Med 1998; 15:539-53.

20 Voss EM, Cembrowski GS. Performance characteristics of the HemoCue B-Glucose analyzer using whole-blood samples. Arch Pathol Lab Med 1993;117:711-3

21 Mooy JM, Grootenhuis PA, De Vries H, Valkenburg HA, Bouter LM, Heine RJ. Prevalence of determinants of glucose intolerance in a Caucasian population: The Hoorn Study. Diabetes Care 1995;18:1270-3.

22 Van Avendonk MJP, Gorter KJ, Van den Donk M, Rutten GEHM. Niet alle huisartsen hebben de praktijkorganisatie om optimale diabeteszorg te leveren. Huisarts Wet 2007;50:529-34.

23 Wilson JMG, Jungner G. Principles and practice of screening for disease. Geneva: World Health Organization, 1968.

24 Unwin N, Shaw J, Zimmet P, Alberti KG. Impaired glucose tolerance and impaired fasting glycaemia: The current status on definition and intervention. Diabet Med 2002; 19:708-23.

25 Coutinho M, Gerstein HC, Wang Y, Yusuf S. The relationship between glucose and incident cardiovascular events: A metaregression analysis of published data from 20 studies of 95,783 individuals followed for 12.4 years. Diabetes Care 1999;22:233-40. 